\title{
Chemical Composition of Essential Oils From Released Coriander Variety (Coriandrum sativum L.) Grown in Ethiopia
}

\author{
Biruk Hirko* Sileshi Abera \\ Ethiopian Institute of Agricultural Research, Tepi Agricultural Research Centre P. O. Box 34, Tepi, Ethiopia
}

\begin{abstract}
The objective of this study was to determine the chemical composition of two coriander variety (Indium and Dinqnesh) produced in Ethiopia. The essential oil content was obtained by hydro distillation method with Clevenger apparatus. The chemical profiles of two varieties were identified using GC-MS. The essential oil content of the dried seeds was $0.60 \%$ for Dinqnesh and $0.50 \%$ for Indium varieties, respectively. About thirty four and fifty one different compounds were identified from essential oil of Indium and Dinqnesh varieties, respectively. Linalool was found to be the principal constituent for both varieties. The variety Indium had higher linalool content $(76.45 \%)$ than Dinqnesh (58.85\%). Other major components identified were Geranyl acetate (5.60\% for Indium and $4.04 \%$ for Dinqnesh variety), $\gamma$-terpinene $(6.76 \%$ for Dinqnesh variety and $2.83 \%$ for Indium) and $\alpha$-pinene $(6.15 \%$ for Dinqnesh and $4.90 \%$ for Indium) were identified. Bicycle $[2,2,2]$ heptan2one, 1,7,7-trimethyl-, (1S) and Benzene, 1-methyl-3-(1-methylethyl) were a compounds found only in Dinqnesh Variety and yielded $6.54 \%$ and $1.28 \%$, respectively. With comparing the chemical composition of both variety essential oil constituents to other origin or standard requirements, both varieties meet the potential for nutritional and export standard requirement.
\end{abstract}

Keywords: Coriander, essential oil, chemical composition, quality

DOI: $10.7176 / \mathrm{CMR} / 11-9-01$

Publication date: November $30^{\text {th }} 2019$

\section{Introduction}

The flavour and aroma of produced from coriander seed is mainly due to its essential oil constituents. Coriander seed oil is found among the 20 major essential oils (Lawrence, 1992) and its commercial need depends on its physical characteristics, chemical constituents and aroma (Smallfield et al., 2001). Linalool is the principal volatile compound found in seeds, containing more than $50 \%$ of the total essential oil (Ramadan and Morsel, 2003). Coriander is economically important spice, due to its biological active compounds found in it. The accumulation and chemical composition of essential oil in plants are governed by different factors: environmental (Rakic and Johnson, 2002; Sriti et al. 2011), genetic (Zheljazkov et al., 2008; Ebrahimi et al., 2010) as well as cultivation practices (Zheljazkov et al., 2008).

Since the chemical compositions of essential oils are the basis for their exploitation, a more attention has to be paid to the variation in the constituents. Coriander has been cultivated in different agro ecology of Ethiopia. The essential oil compositions of coriander fruit samples from Bale and Gondar regions of Ethiopia is reported by Nigist and Birhanu (1998). So far two coriander varieties namely Indium and Dinqnesh which released by Tepi and Debrezeit Agricultural Research Centers collaboratively; their essential oil compositions is not yet studied. Therefore, this study was conducted to determine the essential oil yield and compositions of the two released varieties of coriander

\section{Materials and method}

\subsection{Sample collection}

The seeds of coriander varieties were collected from Kulumsa Agricultural Research Centre during January, 2018 and were transported to Tepi Agricultural Research Centre for the essential oil extraction.

\subsection{Sample extraction}

Essential oil extraction from the coriander seed was performed by the Hydro-distillation in Clevenger apparatus. $100 \mathrm{~g}$ seeds of each powder of coriander varieties with three replicates were set separately in round bottom flask of $2000 \mathrm{ml}$ in which $1000 \mathrm{ml}$ distillate water was added. The process of hydro-distillation lasted for four consecutive hours and oil obtained was stored in a dark glass container until the time of chromatographic separation.

\subsection{Gas chromatography mass spectrometry (GC-MS) analysis}

GC-MS analysis of essential oil composition was identified at Jije analytical testing service laboratory. Essential oil compound identification was depending on comparison of their mass spectra with data of CG-EM (Nist 62 lib.) (Mclafferty and Stauffer, 1989) and retention index of kovats (Adams, 1995). The analysis conditions had a chromatographic system 7890B GC with split/split less mode inlet; equipped with DB-5MS capillary column (30 
$\mathrm{m} \times 0.25 \mathrm{~mm} \times 0.25 \mathrm{~mm}$ ) and detector 5977A MS. The GC experimental conditions functioned with inlet temperature of $260^{\circ} \mathrm{C}$ with injection volume of $1 \mu \mathrm{l}$; column flow of carrier gas Helium $(1 \mathrm{ml} / \mathrm{min})$ and with programmed oven temperature of $40^{\circ} \mathrm{C}$ hold for 3 minutes, then $4^{\circ} \mathrm{C} /$ minutes to $90^{\circ} \mathrm{C}$ hold for 3 minutes by $4^{\circ} \mathrm{C} /$ minutes to $170{ }^{\circ} \mathrm{C}$ hold for 3 minutes, at $6^{\circ} \mathrm{C} /$ minutes to $230^{\circ} \mathrm{C}$ hold for 4 minutes, $10^{\circ} \mathrm{C} /$ minutes to $270^{\circ} \mathrm{C}$ hold for 1 minutes.

\section{Results and discussion}

\subsection{Essential oil yield (\%)}

Hydro-distillation of coriander seeds resulted in $0.60 \%$ and $0.50 \%$ Essential oil for Dinqnesh and Indium varieties, respectively. The result obtained in this study is comparable with many authors report of oil yield between 0.2 and 1.3\% among 36 different Coriander accessions from Austria (Dobos and Novak, 2005); between 0.1 to $0.36 \%$ for Iranian accessions (Nejad et al., 2011); lees than 1\% (Telci et al., 2006) and between 0.5 to $2.5 \%$ (Mahendra and Bisht, 2011). Contradictorily, Zheljazkova et al. (2008) reported the essential oil content 0.8 to $2.2 \%$ from different cultivars of coriander native to Atlantic Canada which is greater than the result obtained in this study.

\subsection{Chemical composition of oil}

A total of 51 and 34 compounds were identified from Dinqnesh and Indium varieties, respectively and presented on table 1 . The essential oil tested contained high amount of linalool (76.45\% for Indium variety and $58.85 \%$ for Dinqnesh variety followed by $\alpha$-pinene $(6.15 \%$ for Dinqnesh variety and $4.90 \%$ for Indium), $\gamma$-terpinene $(6.76 \%$ for Dinqnesh variety and $2.83 \%$ for Indium), geraniol (4.04\% for Dinqnesh and $1.22 \%$ for Indium), geranyl acetate $(5.60 \%$ for Indium and $4.04 \%$ for Dinqnesh variety).

In this study Bicycle[2,2,2] heptan-2one,1,7,7-trimethyl-, (1S) and Benzene, 1-methyl-3-(1-methylethyl) were a compounds found only in Dinqnesh Variety yielded $6.54 \%$ and $1.28 \%$, respectively, (Table 1). From a total of 51 compounds identified from Dinqnesh variety; 17 compounds were not found in Indium variety. However, the percentage of linalool in Indium was very high $(76.45 \%)$ when compared to the linalool percentage of Dinqesh variety (58.85\%). Differently from identified compounds Oleic acid is found only in Indium variety. Raal et al. (2004) analysed the oil of Coriander seeds from different geographical origins of Europe and the major constituent of the oils were reported as linalool $(58.0-80.3 \%), \gamma$-terpinene $(0.3-11.2 \%), \alpha$ pinene $(0.2-10.9 \%), p$-cymene $(0.1-8.1 \%)$, camphor $(3.0-5.1 \%)$ and geranyl acetate $(0.2-5.4 \%)$. The essential oil content of coriander consists mainly linalool (50 to 60\%) and about 20\% terpenes (pinenes, $\gamma$-terpinene, myrcene, camphene, phellandrenes, $\alpha$-terpinene, limonene, and cymene) as reported by Telci et al. (2006). In this study the other compounds identified in the coriander seed oil are D-limonene $(0.73 \%$ for Indium and $3.03 \%$ for Dinqnesh variety), aR- turmerone (1.05\% for Indium and $0.40 \%$ for Dinqnesh variety) and indo-borneol $(0.43 \%$ for Indium and $1.75 \%$ for Dinqnesh variety). Bicycle [2, 2, 2] heptan-2one, 1, 7, 7-trimethyl-, (1S) and Benzene, 1-methyl-3-(1-methylethyl) were the major compounds only found in Dinqnesh variety (Table 1). Table 1. Chemical composition of two varieties essential oils of coriander (coriandrum sativum L.) seeds

\begin{tabular}{clcc}
\hline S/n & \multicolumn{1}{c}{ Name of compounds } & \multicolumn{2}{c}{ Chemical composition (\%) } \\
\cline { 3 - 4 } 1 & 3-carene & Dinqnesh & Indium \\
2 & Bicyclo[3,1,0]hex-2-ene, 2-methyl-5-(1-methylethyl)- & 0.029 & - \\
3 & $\alpha$-pinene & 0.043 & 4.903 \\
4 & Camphene & 6.146 & 0.211 \\
5 & Bicyclo[3,1,0]hexane, 4-methyl-1-(1-methylethyl)- & 1.073 & 0.132 \\
6 & $\beta$-pinene & 0.335 & 0.461 \\
7 & $\beta$-myrcene & 0.479 & 0.314 \\
8 & $\alpha$-phellandrene & 0.906 & - \\
9 & $\alpha$-terpinene & 0.026 & - \\
10 & Benzene, 1-methyl-3-(1-methylethyl)- & 0.068 & - \\
11 & D-limonene & 1.286 & 0.723 \\
12 & Eucalyptol & 3.034 & - \\
13 & B-cis-Ocimene & 0.049 & 0.026 \\
14 & $\gamma$-terpinene & 0.033 & 2.827 \\
15 & Cis-linalooloxide & 6.761 & 0.168 \\
16 & Cyclohexene, 1-methyl-4-(1-methylethylidene) & 0.127 & - \\
17 & Trans-Linalool oxide (furanoid) & 0.791 & 0.093 \\
18 & Linalool & 0.029 & 76.452 \\
19 & Bicycle[2,2,2]heptan-2one, 1,7,7-trimethyl-, (1S) & 58.855 & - \\
20 & Cyclohexanol, 1-methyl-4-(methylethenyl)- & 6.542 & -
\end{tabular}




\begin{tabular}{|c|c|c|c|}
\hline 21 & Citronellal & 0.146 & 0.057 \\
\hline 22 & Pinocarvone & 0.046 & - \\
\hline 23 & $\alpha$-Campholenal & 0.028 & - \\
\hline 24 & Endo-Borneol & 1.763 & 0.429 \\
\hline 25 & Terpinen-4-ol & 0.233 & 0.082 \\
\hline 26 & L-alpha-Terpineol & 0.656 & 0.163 \\
\hline 27 & Bicyclo[3,1,1]hept-3-ene-2-one,4,6,6-trimethyl- & 0.063 & - \\
\hline 28 & 2,6-Octadien-1-ol, 3,7-dimethyl-, (Z)- & 0.032 & - \\
\hline 29 & Citronellol & 0.339 & - \\
\hline 30 & 2,6-Octadienal, 3,7-dimethyl-,(Z)- & 0.038 & - \\
\hline 31 & Geraniol & 4.022 & 1.197 \\
\hline 32 & Citral & 0.048 & 0.027 \\
\hline 33 & Thymol & 0.021 & 0.034 \\
\hline 34 & 1-Naphthalenol, decahydro-4a-methyl- & 0.029 & 0.056 \\
\hline 35 & Myrtenyl acetate & 0.371 & 0.109 \\
\hline 36 & 6-Octen-1-ol, 3,7-dimethyl-, acetate & 0.028 & - \\
\hline 37 & Geranyl acetate & 4.034 & 5.609 \\
\hline 38 & Dodecanal & 0.034 & 0.047 \\
\hline 39 & Caryophyllene & 0.069 & 0.113 \\
\hline 40 & 2- Dodecenal,(E) & 0.14 & 0.547 \\
\hline 41 & Benzene, 1-(1,5-dimethyl-4-hexenyl)-4-methyl- & 0.042 & - \\
\hline 42 & $\begin{array}{l}\text { (1S,5S)-2-Methyl-5-((R)-6-methylhept-5-en-2- } \\
\text { yl)bicycle[3,1,0]hex-2-ene }\end{array}$ & 0.036 & 0.058 \\
\hline 43 & $\begin{array}{l}\text { Cyclohexane, 3-(1,5-dimethyl-4-hexenyl)-6-methylene-,[S- } \\
\left.\left(\mathrm{R}^{*}, \mathrm{~S}^{*}\right)\right]-\end{array}$ & 0.038 & 0.113 \\
\hline 44 & $\begin{array}{l}\text { (3S,3Ar,3Br,4S,7R,7aR)-4-isopropyl-3,7 dimethyloctahydro- } \\
\text { 1H-cyclopenta[1,3]cyclopropa[1,2]benzene-3-ol }\end{array}$ & 0.032 & - \\
\hline 45 & aR-Turmerone & 0.40 & 1.049 \\
\hline 46 & Tumerone & 0.151 & 0.209 \\
\hline 47 & (E)-Tetradec-2-enal & 0.027 & 0.285 \\
\hline 48 & Curlone & 0.165 & 0.285 \\
\hline 49 & Tetradecanoic acid & 0.136 & 0.032 \\
\hline 50 & 2-pentadecanone, 6,10,14-trimethyl- & 0.023 & 0.045 \\
\hline 51 & n-Hexadecanoic acid & 0.164 & 0.119 \\
\hline \multirow[t]{2}{*}{52} & Oleic acid & & 0.039 \\
\hline & Total & 100 & 97.014 \\
\hline
\end{tabular}

Among the common chemical constituents, the Dinqnesh variety oil contains the highest $\gamma$-terpinene (6.67\%), Bicycle [2,2,2] heptan-2one, 1,7,7-trimethyl-, (1S) (6.54\%), $\alpha$-pinene $(6.15 \%)$, Geraniol (4.02\%), Dlimonene (3.03\%), Endo-Borneol (1.76\%), Benzene, 1-methyl-3-(1-methylethyl)-(1.28\%) and camphene (1.07\%) than the Indium variety. However the constituents of oil in Indium variety was higher for linalool $(76.45 \%)$, Geranyl acetate $(5.61 \%)$ and aR-Turmerone (1.04) than for Dinqnesh variety. The results obtained showed the compounds variation from other country variety when we compare with author report. This may be due to climate, soil condition and genotype difference. 


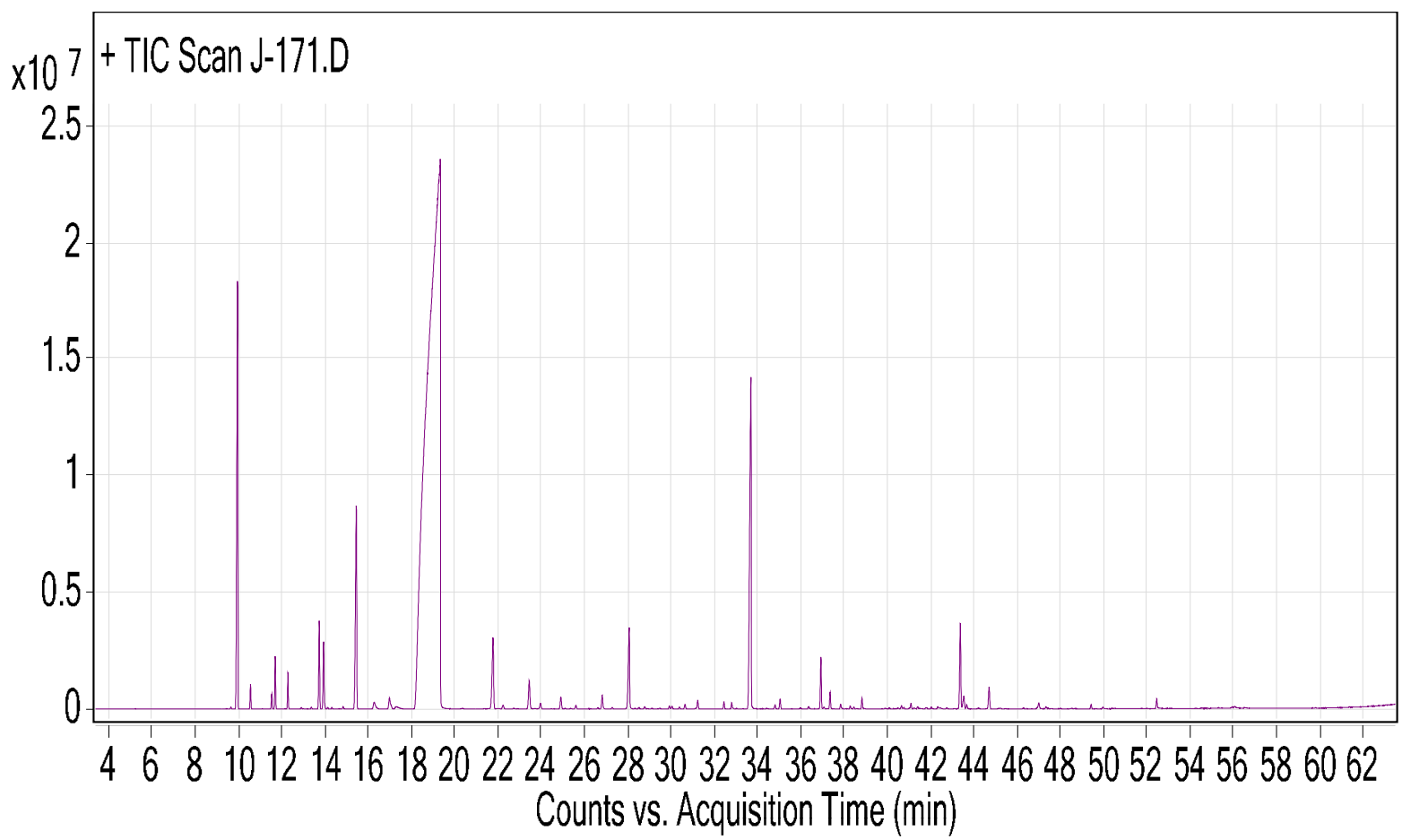

Figure 1. GC chromatogram of indium variety essential oil

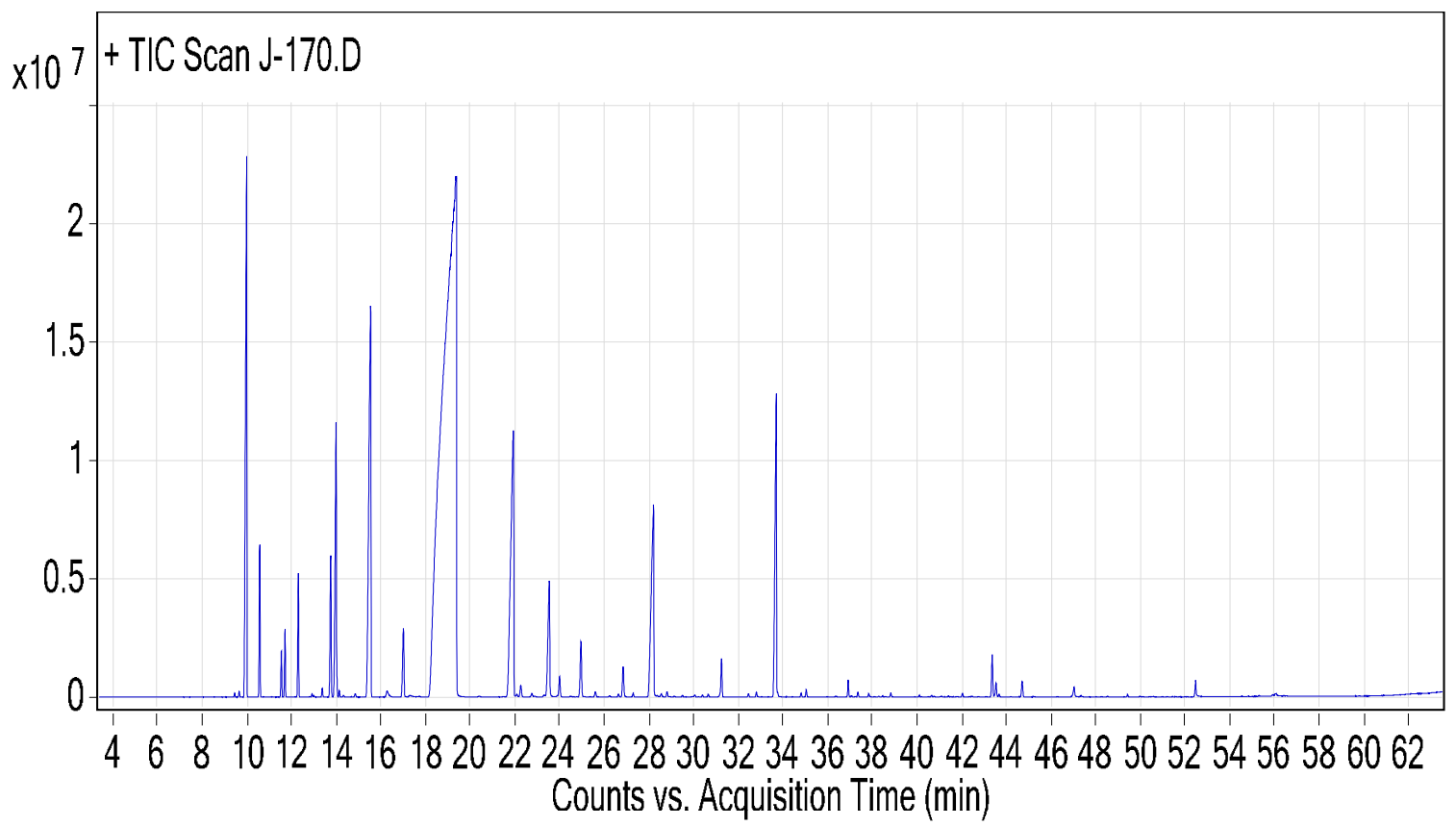

Figure 2. GC chromatogram of Dinqnesh variety essential oil

\section{Conclusion}

Essential oil composition depends on genetic and ecological conditions affecting the plants. The results obtained indicated variation on coriander seed essential oil from two varieties cultivated in the same agro-ecological conditions. In our study Linalool (58.85-76.41\%), Geranyl acetate $(4.04-5.60 \%), \gamma$-terpinene $(2.83-6.76 \%)$ and $\alpha$-pinene $(4.90-6.15 \%)$ were found as major components are responsible for the character of fragrance and aroma of the coriander. The results showed the Ethiopian coriander had met the international standard for essential oil and is competitive for export to international market.

\section{Conflict of interest}

The authors would like to declare that this study was carried out mainly for academic research purpose without any conflict of interest. 


\section{Acknowledgements}

The author would like to thank the Ethiopian Institute of Agricultural Research for funding the research and JIJE Analytical Testing Service Laboratory for GC-MS analysis.

\section{References}

Adams, R.P. 1995. Identification of essential oil components by gas chromatography/mass spectroscopy. Carol Stream: Allured, 1995. 469p.

Aissaoui, A., Zizi, S., Israili, Z.H. and Lyoussi, B. 2011. Hypoglycemic and hypolipidemic effects of Coriandrum sativum L. in Merionesshawi rats, Journal of Ethnopharmacology, 137(1), 652-661.

Bown, D. 1995. The Royal Horticultural Society Encyclopedia of Herbs and Their Uses, Dorling Kindersley Ltd. London, p. 424.

Delaquis, P.J., Stanich, K., Girard, B. and Mazza, G. 2002. Antimicrobial activity of individual and mixed fractions of dill, cilantro, coriander and eucalyptus essential oils, International Journal of Food Microbiology, 74(1-2), 101-109.

Dobos G, Novak J. 2005. Comparison of the composition of the essential oil of some winter-annually cultivated coriander accessions (Coriandrum sativum L.). Zeitschrift fur Arznei- and Gewurzpflanzen;10:144-145.

Ebrahimi, E.S., Hadian, J. and Ranjbar, H., 2010. Essential oil compositions of different accessions of Coriandrum sativum L. from Iran. Natural product research, 24(14), pp.1287-1294.

Lawrence, BM.1992. A planning scheme to evaluate new aromatic plants for the flavor and fragrance industries. In: Janick, J.; Simon, J.E., editors. New Crops: exploration, research, and commercialization. Proceedings of the Second National Symposium; John Wiley and Sons, Inc., NewYork. p. 620-627.

Mahendra P., BishtS. 2011. Coriandrum sativum: A daily use spice with great medicinal effect. Pharmacognosy Journal, 3 (21): 84-88.

Mclafferty, F.W.; Stauffer, D.B. 1989. The wiley/NBS registry of mass spectral data. New York: Hardback, $7872 \mathrm{p}$.

Mhemdi H, Rodier E, Kechaou N, Fages J 2011. A supercritical tuneable process for the selective extraction of fats and essential oil from coriander seeds. J. Food Eng. 105(4):609-616.

Mohammadi S., Saharkhiz M.J. 2011. Changes in essential oil content and composition of catnip (NepetacatariaL.) during different developmental stages. J. Essent. Oil Bear. Pl. 14 (4): 396-400.

Msaada, K., Hosni, K., Taarit, B.M., Chahed, T., Kchouk, E.M. and Marzouk, B. 2007. Changes on essential oil composition of Coriander (Coriandrum sativum L.) fruits during three stage of maturity", Food Chemistry, $102,1131-1134$.

Raal A, Arak E, Orav A. 2004. Chemical composition of coriander seed essential oil and their conformity with EP standards. Agraarteadus 15:234-239.

Rajeshwari, C.U.,Siri, S. and Andallu, B. 2012. "Antioxidant and anti arthritic potential of coriander (Coriandrum sativum L.) leaves", e-SPEN Journal, 7(6), 223-228.

Silva F, Ferreira S, Queiroz JA, Fernanda CD 2011. Coriander (Coriandrum sativum L.) essential oil its antibacterial activity and mode of action evaluated by flow cytometry. J. Med. Microbiol. 60:1479-1486.

Small field BM, Van Klink JW, Perry NB, Dodds G. 2001. Coriander spice oil: effects of fruit crushing and distillation time on yield and composition. Journal of Agriculture and Food Chemistry;49:118-123.

Sriti J., Wannes W. A., Talou T., Vilarem G., Marzouk B. 2011. Chemical composition and antioxidant activities of Tunisian and Canadian coriander (Coriandrum sativumL.) fruit. J. Essent. Oil Res. 23 (4): 7-15.

Telci I, Gul TO, Sahbaz N. 2006. Yield, essential oil content and composition of Coriandrum sativumvarieties (var. vulgare Alef and var. microcarpumDC.) grown in two different locations. Journal of Essentl Oil Research; 18: 189-193.

Zheljazkov V.D., Pickett K.M., Caldwell C. D., Pinocock J.A., Roberts J.C., Mapple- Beck L. 2008. Cultivar and sowing date effects on seed yield and oil composition of coriander in Atlantic Canada. Industrial Crops Prod., 28: 88-94 